Laboratory simulation of the influence of groundwater rise and drip irrigation on the settlement of a sample of collapsible desert soil

Ramesh Vandanapu, (Corresponding author)

PhD Student, School of Natural and Built Environments, Kingston University London, UK K1452539@kingston.ac.uk,Tel: +971559434709

Assistant Professor in Civil Engineering, Amity University, Dubai, U.A.E ramesh.vandanapu@gmail.com

Joshua R. Omer

Senior Lecturer, School of Natural and Built Environments, Kingston University London, UK

Mousa F. Attom

Professor, Department of Civil Engineering, American University of Sharjah, U.A.E.

Word count: 5091(inclusive of title, author affiliations, abstract, tables, references, figure captions) 


\title{
Laboratory simulation of the influence of groundwater rise and drip irrigation on the settlement of a sample of collapsible desert soil
}

\begin{abstract}
In the dry, dense and well-graded states, most sands and sandy gravels generally have low susceptibility to settlement under loading. However, certain sands when increasingly saturated, exhibit a decrease in suction and tensile strength hence leading to a sudden decrease in volume. Soils having such characteristics are known as collapsible soils and are predominantly encountered in arid and semi-arid regions. They require special consideration because conventional elastic/empirical settlement analysis methods may not be adequate for them. Intensively irrigated landscapes overlying collapsible strata have recently been linked with severe settlement and damage to buildings, roads and other infrastructure in Abu Dhabi city. This paper presents a laboratory simulation of the settlement response of a collapsible sand layer sandwiched between two other layers inside a metal mould and loaded with a constant surcharge while varying water infiltration rates and static water levels. The primary goal of the research is to simulate the loaded behaviour of real collapsible soils in the field and develop a method of predicting the settlement resulting from such behaviour. Finally empirical relationships are formulated for estimating settlement of a collapsible layer as a function of the layer thickness, position of groundwater table and irrigation intensity and duration.
\end{abstract}

Keywords: Collapsible soil, Laboratory simulation, Deformation, Drip irrigation

\section{Introduction}


Collapsible soils are of a special kind in that they exhibit a decrease in suction and tensile strength when they are sufficiently saturated. Hence this leads to a sudden decrease in volume and consequently settlement. Collapsible soils are usually characterized by high void ratio, low density, openness in structure, high porosity and low degree of saturation (Noutash et al. 2010). Soils of this type are found in many parts of the world such as USA, Central and South America, China, Africa, Russia, India and the Middle East (Murthy 2010). Collapsible soils usually exist in shallow deposits and water ingress is the most salient reason for their abrupt reduction in volume occasioning structural collapse (Jotisankasa 2005). Water ingress can be through rainfall, continuous pipeline leakages, intensive landscape irrigation or large spillages at the surface. Despite having reasonable bearing capacity in the dry state, the tendency of collapsible soils to deform significantly and loose strength upon saturation poses special challenges to geotechnical engineers (Rezaei et al. 2012). Most types of collapsible sands consist primarily of silt sized particles (Kalantari 2012) and occur in arid and semi-arid regions. In arid regions, high temperatures mean that the ground dries off rapidly and evaporation rates are high, thus there is very little time for underlying collapsible soil layers at superficial levels to consolidate under the prevailing overburden (Pye and Tsoar 1990).

The mechanisms of collapsible soils can be appreciated by considering how wetness destroys the metastable structure of the soil, with resulting breakage of bonds between the soil grains, leading to re-arrangement of soil particles into a denser mass hence volume reduction (Barden et al. 1973; Mitchell 1976; Jotisankasa 2005; Bolzon 2010). It should be noted that collapsible soils are not a particular type of soil, but are soils that are prone to structural collapse through loss of inter-particle friction (Kalantari 2012). Naturally collapsible soils usually exist in the unsaturated state (Zhu and Chen 2009) hence their prevalence in arid and semi-arid regions. It should also be understood that such soils require only a relatively short period of time to reach the collapse state when saturation levels are sufficiently high. In practice, the 
existence of collapsible soil deposits in close proximity to a water source has been found to create problems for ground bearing infrastructures such as pipelines, roads and buildings which can suffer damage due to excessive ground settlement.

Houston et al. (1993) suggested that, even when not 100\% saturated, certain soils may exhibit partial collapse behaviour, but Houston et al. (2002) contended that full saturation is necessary for complete collapse to take place. Khalili et al. (2004) conducted extensive tests and effective stress analysis on undisturbed clays from the site of Hume Dam, south-eastern Australia, and concluded that the settlement of the soil was largely due to a reduction in the yield stress. Houston et al. (1995) developed a “downhole collapse test” by placing a plate in a drilled borehole, adding water to the hole and applying incremental loading to the plate to measure load-settlement response. This led to equations for estimating the soil collapse due to wetting. Whilst such a practical test is consistent with reality, the cost involved may be undoubtedly too high and unjustified for some small projects. Notwithstanding the complexity of mechanisms involved in soil structural collapse, attempts have been made by various researchers (Holtz and Hilf 1961; Jennings and Knight 1975; Jasmer and Ore 1987; Tadepalli et al. 1992; Anderson and Reimer 1995; Reznik 2007; Gaaver 2012; Kalantari 2012; Rezaei et al. 2012) to experimentally assess and characterize the deformation behaviour of certain collapsible soil types in laboratory conditions.

Much of the laboratory work carried out by the above mentioned authors concentrated on: (a) undisturbed soil samples, which contrasts the situation with ground conditions in the UAE (United Arab Emirates) region, where most superficial deposits are non-cohesive silty sands that are extremely difficult to extract as undisturbed and (b) soils that are either perfectly dry or fully saturated yet this is obviously inconsistent with real situations where alternate cycles of drought, rainfall and other infiltration causing events are to be expected. Therefore, in this paper, an attempt is made to devise test conditions which are as representative as possible 
of actual ground situations in the UAE. The laboratory tests carried out in this research seek to examine and quantify how variations in groundwater levels and relative depths and thicknesses of a collapsible stratum influence settlement, for given rates of water infiltration and magnitudes of surface surcharge.

\section{Experimental arrangements}

From the outset, the challenge was to improvise a simple, cost-effective yet reasonable test arrangement to fit in the limited laboratory space available. Regardless of the equipment constraints, the experiment had to yield good enough data to enable understanding of the influence of controlled water levels, surcharges and stratum thickness on the settlement behaviour of a collapsible soil layer bounded by two free-draining layers. It was proposed to use a water supply tank fitted with "infusion bottles" with controllable rates of discharge. This was to simulate intensity of landscape irrigation and consequent water level rises within a subsurface profile comprising a collapsible stratum. A metal mould, of the same type specified for a standard CBR (California Bearing Ratio) test in BS 1377-4:1990, was used to cast a threelayer soil profile with each layer compacted to pre-determined densities. A maintained surcharge of $4.54 \mathrm{~kg}$ was applied on the top of the uppermost soil layer in the CBR mould. The middle layer was formed from a specimen of collapsible soil obtained from some of the boreholes that had been drilled by a Geotechnical consultant in a part of Abu Dhabi City, where structural damage had been observed (Vandanapu et al. 2016) to be linked to irrigation-induced settlement of collapsible soil strata at depth. As reported by Vandanapu et al. (2016) signs of structural distress were detected in footpaths, road pavements and perimeter walls that were located close to irrigated lawns. No signs of distresses were noticed in residential villas and buildings since these were supported on piles penetrating collapsible strata and extending down to the rock head below. 


\section{Soil profiles and relative thicknesses in test model}

In order to generate adequate data to tackle the objectives of the research, the settlement response of a collapsible soil specimen was measured by casting the soil to different thicknesses in a CBR mould under different water levels. Four soil profile cases: SC-1, SC-2, SC-3, and SC-4 were formed in moulds by casting the collapsible layer in between two layers of free-draining, non-collapsible types of sand. For each soil combination (SC), the overall thickness of the three soil layers in the mould was kept constant $(\mathrm{H})$, as shown in Table 1 . The difference in the four cases was is the thickness of the collapsible layer, which was set at $H / 2$, H/3, H/4 and H/5 as shown in Table 1 . For each soil combination, load-settlement data were measured for three compacted densities: $17.5 \mathrm{kN} / \mathrm{m}^{3}, 18.0 \mathrm{kN} / \mathrm{m}^{3}$ and $18.5 \mathrm{kN} / \mathrm{m}^{3}$. Furthermore, for each density case tests were run with water filled to three different heights of water in the mould, i.e. H/3, H/2 and 2H/3 from bottom of mould. Thus, a total of 36 tests were conducted. The intention was to recreate as far as possible the ground situation in the locations from where the collapsible soils were sampled, as part of the investigation of structural distress witnessed in a certain UAE region. Details about experimental set-up, materials, and instrumentation specifications are described in the forthcoming sections.

\section{Experimental test set-up}

Before casting soils in the CBR moulds, a filter paper was inserted at the bottom of the mould to prevent soil particles from clogging the perforations in the bottom plate of the mould. Weighed amounts of each soil type were carefully placed and compacted in the moulds to desired thicknesses and densities. The moulds containing the compacted soils were then placed inside a wide-bottomed plastic tank in which water could be added to desired levels, as shown in Fig. 1. This was done in an effort to simulate field conditions where the settlement of a collapsible stratum is influenced differently by different ground water table depths. To ensure easy entry of water into the moulds through the perforations, adequate care was taken to keep 
the underside of the mould sufficiently clear from the base of the tank by using a thin spacer disc or seat.

Infusion sets were used to trickle water at controlled and measurable rates onto the top layer in the mould. This was to simulate the typical irrigation rates $\left(\mathrm{m}^{3} / \mathrm{m}^{2} / \mathrm{s}\right)$ applied for lawns and landscapes in the areas of the UAE where settlement of subsurface collapsible strata had caused structural damage due to sustained water infiltration. With the free-draining nature of the top and bottom layers, the water level in the soil inside the moulds could quickly stabilize and match that in the tank. Using a swell plate and gauge tripod assembled as shown in Fig. 2, settlements of the top soil surface were measured at close intervals of time as the water table was varied while continuing drip irrigation with the infusion sets at specific discharge rates.

\section{Selection and preparation of the collapsible soil specimen}

Following extensive ground investigations carried out by geotechnical contractors, collapsible soils in various areas around Abu Dhabi, UAE, were revealed as the reason for the distresses and damages caused to various shallowly founded structures. The settlement of the collapsible soil layers in the field was mainly due to deep percolation of water from human activities related to irrigation of lawns and landscapes around properties. From the ground investigations, borehole logs were produced which identified water levels as well as depth locations of collapsible strata where low SPT (Standard Penetration Test) values (from $\mathrm{N}<4$ to $4<\mathrm{N}<10$ ) were encountered. Samples of the collapsible soils were collected from the field and made available for the present research. Representative samples of the collapsible soil from 12 exploratory boreholes were subjected to sieve analysis, from which the particle size distribution was plotted as shown in Fig. 3. The thick continuous curve shows the mean particle size curve. The depth locations of the extracted samples as well as the corresponding SPT values are clearly shown in the legend of Fig. 3, in the format: (depth, SPT N-value). For example (4$4.45 \mathrm{~m}, 8)$ indicates that the soil sample was obtained at a depth of $4.00-4.45 \mathrm{~m}$ using split spoon 
sampler and the SPT value measured was $\mathrm{N}=8$. Due to the large quantity of soil required for this research, the enormous task of sieving the collapsible soils from numerous boreholes was outsourced to a specialist company. Upon receipt of the soil samples from the company, a range of laboratory tests were carried out on them to determine the basic properties, which are reported in Table 2 along with the sampling depth locations and borehole references.

\section{Simulation of groundwater table}

As previously stated, most researchers have concentrated on measuring settlement of collapsible soil in either dry or fully saturated conditions, despite such conditions being scarcely applicable to the natural environment in the ground. In the present work, the starting point was to fill the moulds with calculated weights of dry soils and statically compact them to the predetermined overall depth, $\mathrm{H}$, in the mould hence achieving the targeted density. Thereafter, swell plate along with surcharge weights are placed and initial reading was taken using gauge tripod. The moulds were then placed in the plastic tank, to which water was added gradually to the target depths $\mathrm{H} / 3, \mathrm{H} / 2,2 \mathrm{H} / 3$ from the bottom of mould. Using the dial gauges, settlements of the top soil surface were measured and recorded continuously from the dry soil state until achievement of the target water depth. The measurements were continued until cessation of settlement as water seeped from the perforated plate at the bottom of mould. The

difference between the initial dial gauge reading (with the soil still in the dry state) and the final reading upon cessation of settlement was attributed to the settlement induced by the water table rise.

\section{Simulation of rates of landscape irrigation}


Once the settlement due to rise in water table alone was established, further testing was undertaken to measure the soil settlement caused by the drip irrigation alone. To do this, a valve controlled infusion set was connected to an inverted water bottle opened at the top and filled with water as shown in Fig. 1. Then the bottom end of the bottle, through which water exited via the infusion tube, was directed over the moulds and moved in uniform patterns to distribute water evenly on the soil surface in cycles of irrigation. A cycle was defined as discharge of water at a constant rate of rate of 13 litres $/ \mathrm{m}^{2} /$ day maintained for 30 minutes and repeated every 12 hours. These figures were selected to be consistent with the data on irrigation rates and patterns obtained from local landscaping contractors operating in the areas of UAE where settlement related damage was caused to infrastructure. Most of the irrigation contractors watered the ground twice a day $(6.00 \mathrm{am}$ to $6.30 \mathrm{am}$ and $6.00 \mathrm{pm}$ to $6.30 \mathrm{pm})$ uniformly at a spreading rate of 6.5 litres $/ \mathrm{m}^{2}$. For the laboratory tests here, a trial and error approach was used and refined several times to find the equivalent rate of discharge which would be applicable to the surface area of the soil in the mould. The trials were done by altering the setting the flow control valve of the infusion sets and using a stopwatch to note the time durations of the drips applied.

Settlements of the top soil surface were recorded continuously until there was virtually no difference $(\leq 0.01 \mathrm{~mm})$ in settlement magnitude for two consecutive irrigation cycles. This was deemed to be a stable state for the settling soils. In order to maintain a constant discharge during an irrigation cycle, it was necessary to compensate for the gradually reducing head of water, as the drip cycle processed, by continuously feeding in more water through the open bottle top. At the end of the test, the settlement of soil due to drip irrigation alone was calculated by subtracting the dial gauge reading at the time before drip cycles commenced from the reading at completion of the drip cycles.

\section{Test results and discussions}


Data from the 36 test runs were presented in graphical format typifying trends of variation between:

(i) Surface settlement due to rise in water level only and normalized water depth (water table factor), for each of the three compacted densities and for each of the four soil strata combinations (Fig. 4)

(ii) Surface settlement due to rise in water level only and water table factor, for an average value of compacted densities and for each of the four soil strata combinations (Fig. 5)

(iii) Surface settlement due to drip irrigation only and water table factor, for an average value of compacted densities and for each of the four soil strata combinations (Fig. 6)

(iv) Surface settlement due to combined rise in water level and drip irrigation and water table factor, for an average value of compacted densities and for each of the four soil strata combinations (Fig. 7)

(v) Average surface settlement due to rise in water level only and thickness of collapsible layer (Fig. 8)

(vi) Average surface settlement due to combined rise in water level and drip irrigation and thickness of collapsible layer (Fig. 9)

For purposes of normalization, the 'water table factor' was defined as the ratio of water table depth to the overall thickness of the soils in the mould. Thus the water table factor is plotted as a dimensionless quantity. 
As can be seen in Fig. 4 for all compacted densities, the soil settlement increased with increasing depth of the water table. This was attributed to an increasing proportion of soil mass gaining higher saturation degrees due to gradual ingress of water. Also, at any density level, settlement increased with increasing thickness of the collapsible soil within the profile. This was attributable to a correspondingly greater thickness of collapsible soil being influenced by the infiltration water. In addition, it can be seen that in overall terms, increase in the compacted density resulted in decrease in settlements. This was anticipated because the low air voids in the dense soil obviously meant decreased potential for the particles to re-adjust or deform further upon ingress of water.

Furthermore, of all the soil profile combinations, the maximum settlement of $7.72 \mathrm{~mm}$ was observed in SC-1, at water table factor of 2/3, highest thickness of collapsible soil layer and maximum water table height. Thus this may be regarded as the most critical combination of factors for the collapsible to settle the most. For this case, it was observed that with a density increase from $17.5 \mathrm{kN} / \mathrm{m}^{3}$ to $18.5 \mathrm{kN} / \mathrm{m}^{3}$ the settlement decreased by a factor of $1.8(7.72 \mathrm{~mm}$ to $4.29 \mathrm{~mm}$ ). The observation here suggests that the in-situ density of a collapsible stratum is crucially important in influencing the stability of the soil structure and hence settlement potential. For this reason it is imperative that densification by deep compaction is likely to be the most effective ground improvement technique to reduce settlement problems related to collapsible soil strata under the influence of water.

\section{Variation of settlement with normalized water table depth for average compacted soil}

\section{density}

The graph in Fig. 5 represents the variation trend for settlement versus water depth for averaged soil density. It can be seen that in general settlement still increased with increasing water table depth as was observed for different densities in Fig. 4. However, there was no significant difference in settlement in profile cases SC-3 and SC-4 at a normalized water depth of 1/3. 
This happened because, despite the differences in the thickness of collapsible soil layers in cases SC-3 and SC-4, the water level was still below the collapsible stratum hence unaffected by it. However, the slight increase in average settlement from 1.35 to 1.41 could be attributed to the capillary rise of water due to the close proximity of the collapsible soil to the water level.

\section{Variation of settlement due to drip irrigation with water level}

In Fig. 6 the aim was to study collapse settlements due to drip irrigation after the attainment of the full settlement caused by rises in the water table level. Further settlements as drip irrigation continued was expected because once the soils below the water table had reached collapse stage, the parts above the water table were still being wetted by irrigation water hence progressively causing additional collapse. It can be seen in Fig. 6 that due to drip irrigation alone, the settlement decreased with increasing water table factor. This contrasts sharply with the previous observation that settlement due to rise in water table alone increased with increasing water table factor. The reason was that when large portions of the collapsible layer was already under water, the less saturated upper parts were rather too thin to give further settlement even under drip irrigation.

\section{Variation of settlement due to combined effects of water level rise and drip irrigation}

The combined effect of rise in water table and drip irrigation on settlement on soil is shown in Fig. 7. Here, the settlement behaviour is essentially similar to that due to rise in water table only. Thus it is apparent that settlement of collapsible soils is influenced much more by the water table depth than by irrigation process, provided that much of the layer is already submerged.

\section{Settlement predictions}


It can be seen from Fig. 8 and 9 that there is an increase in settlement with increase in the thickness of the collapsible layer. This happens due to water table rise alone (Fig. 8) as well as due to combined rise in water table and drip irrigation (Fig. 9). Under the combined influence of water table rise and drip irrigation, the surface settlement increases with decreasing density of soil, irrespective of the thickness of collapsible soil. A similar pattern of behaviour is exhibited at higher thickness of collapsible stratum $(120 \mathrm{~mm})$, due to rise in water table alone. It is seen that, at lower thicknesses $(60 \mathrm{~mm}$ and $90 \mathrm{~mm})$, the settlement behaviour is markedly different. This is attributable to the fact that the water table rise now affects only a partial zone of the collapsible layer, rather than the full height of the layer. With more extensive data points, curve fitting techniques can be used to model distinct trends of variation between thickness of collapsible soil and average surface settlement, for effects of: (a) rise in water table alone and (b) combined rise in water table and drip irrigation. The models can then be applied to real problems in predicting settlement, for known thickness and properties of the collapsible layer. Settlement due to drip irrigation alone can be predicted as the difference between the corresponding values modelled from Fig. 8 and 9.

\section{Conclusions}

(1) The surface settlement of the soil profile was found to increase with increasing water table factor irrespective of the density of the layers.

(2) For all soil density values examined, the settlement at the surface was found to increase with increase in thickness of the collapsible layer in the profile.

(3) The settlement decreased with increase in density of soil in such a manner that a $1 \mathrm{kN} / \mathrm{m}^{3}$ increase in density of soil caused the surface settlement to decrease by a factor of 1.8.

(4) In the absence of drip irrigation, the surface settlement increased with increasing water levels. However, under the effect of drip irrigation alone, the settlement decreased with increasing water table factor. 
(5) From the graphs of results, modeled relationships between the magnitude of settlement and thickness of collapsible soil can be used to predict the magnitude of ground settlements in real field situations, provided the thickness of the collapsible soil layer and properties of other layers in the profile are available from borehole investigations.

The present work is part of an on-going research project aimed at deepening knowledge of the settlement behaviour of a collapsible sand stratum when under the influence of irrigationinduced infiltration and overburden pressure. It is hoped that a further article will be produced focussing on numerical solutions and construction guidelines to engineers and property owners / irrigation contractors in regions where collapsible soils pose risks to infrastructure.

\section{References}

Anderson, S.A., and Riemer, M.F. 1995. Collapse of saturated soil due to reduction in confinement, Journal of Geotechnical Engineering, 121, (2), 216-219. doi:http://dx.doi.org/10.1061/(ASCE)0733-9410(1995)121:2(216) 
Barden, L., McGown, A. and Collins, K. 1973. The collapse mechanism in partly saturated soil, Engineering Geology, 7, (1), 49-60. doi:http://dx.doi.org/10.1016/0013$\underline{7952(73) 90006-9}$

Bolzon, G. 2010. Collapse mechanisms at the foundation interface of geometrically similar concrete gravity dams, Engineering Structures, 32, (5), 1304-1311. doi:https://doi.org/10.1016/j.engstruct.2010.01.008

Gaaver, K.E. 2012. Geotechnical properties of Egyptian collapsible soils, Alexandria Engineering Journal, 51, 205-210. doi:http://dx.doi.org/10.1016/j.aej.2012.05.002

Holtz, W.G. and Hilf, J.W. 1961. Settlement of soil foundations due to saturation, Proceedings of $5^{\text {th }}$ International Conference on Soil Mechanics and Foundation Engineering, Paris, 1, $673-679$.

Houstan, S.L., Houston, W.N. and Lawrence, C.A. 2002. Collapsible soil engineering in highway infrastructure development, Journal of Transportation Engineering, 128, (3), 295300. doi:http://dx.doi.org/10.1061/(ASCE)0733-947X(2002)128:3(295)

Houston, S.L., Hisham, H.H.M. and Houston, W.N. 1995. Down-hole collapse test system, Journal of Geotechnical Engineering, 121, (4), 341-349. doi: http://dx.doi.org/10.1061/(ASCE)0733-9410(1995)121:4(341).

Houston, W.N., Mahmoud, H.H. and Houston, S.L. 1993. Laboratory procedure for partialwetting collapse determination, Unsaturated Soils, ASCE, New York, USA, Special Geotechnical Publication, 39, 54-63.

Jasmer, R. and Ore, H.B. 1987. Hydro-compaction hazards due to collapsible loess in SouthEastern Idaho, Proceedings of the $23^{\text {rd }}$ symposium on Engineering Geology and Soils Engineering, Logan, Utah, 461-475.

Jennings, J.E., Knight, K. 1975. A guide to construction on or with materials exhibiting additional settlements due to collapse of grain structure. Proceedings of $6^{\text {th }}$ regional 
conference for Africa on Soil Mechanics and Foundation Engineering, Johannesburg, 99105.

Jotisankasa, A. 2005. Collapse behavior of a compacted silty clay, $\mathrm{PhD}$ Thesis, Imperial College, London.

Kalantari, B. 2012. Foundations on collapsible soils: A review. Proceedings of the Institution of Civil Engineers - Forensic Engineering, 166, (FE2), 57-63. http://dx.doi.org/10.1680/feng.12.00016

Khalili, N., Geiser, F. and Blight, G.E. 2004. Effective Stress in Unsaturated Soils: Review with New Evidence, International Journal of Geomechanics, 4, (2): 115-126. https://doi.org/10.1061/(ASCE)1532-3641(2004)4:2(115)

Mitchell, J.K. 1976. Fundamentals of Soil Behavior, New York: Wiley.

Murthy, V.N.S. 2010. Soil mechanics and foundation engineering, New Delhi : CBS publishers and distributors.

Noutash, M.K., Hajialilue, B.M. and Cheshmdoost, M. 2010. Prepounding of canals as a remediation method for collapsible soils, Proceedings of the $4^{\text {th }}$ International Conference on Geotechnical Engineering and Soil Mechanics, Tehran, Iran.

Pye, K. and Tsoar, H. 1990. Aeolian sand and sand dunes. London: Unwin Hyman.

Rezaei, M., Ajalloeian, R. and Ghafoori, M. 2012. Geotechnical properties of problematic soils: emphasis on collapsible cases, International Journal of Geosciences, 3, (1), 105110. http://dx.doi.org/10.4236/ijg.2012.31012

Reznik, Y.M. 2007. Influence on physical properties on deformation characteristics of collapsible soils, Engineering Geology, 92, (1-2), 27-37. http://dx.doi.org/10.1016/j.enggeo.2007.03.001 
Tadepalli, R., Rahardjo, H. and Fredlund, D.H. 1992. Measurement of matric suction and volume changes during inundation of collapsible soil, Geotechnical Testing Journal, 15, (2), 115-122. https://doi.org/10.1520/GTJ10233J

Vandanapu, R., Omer, J.R. and Attom, M.F. 2016 Geotechnical case studies: emphasis on collapsible soil cases, Proceedings of the Institution of Civil Engineers - Forensic Engineering, 169. (3). 103-110. http://dx.doi.org/10.1680/jfoen.16.00011

Zhu, Y. and Chen, Z. 2009. A new method of studying collapsibility of loess, Frontiers of Architecture and Civil Engineering in China, 3, (3), 305-311. http://dx.doi.org/10.1007/s11709-009-0040-3.

\section{Figure captions}

Fig. 1 Purpose designed experimental arrangement for measuring settlement of collapsible soil under varying irrigation rates and water levels

Fig. 2 Monitoring of the initial gauge readings for soil in the dry state prior to start of irrigation

Fig. 3 Grain size distributions of representative collapsible soil samples from 12 boreholes (sampling depths and SPT values shown in the legend)

Fig. 4 Variation between soil settlement due to water table rise and water table factor (results for different soil densities: $17.5-18.5 \mathrm{kN} / \mathrm{m}^{3}$ )

Fig. 5 Variation between average soil settlement due to water table rise and water table factor

Fig. 6 Variation between average soil settlement due to drip irrigation and water table factor

Fig. 7 Variation of average soil settlement with water table factor due to the combined effects of water table rise and drip irrigation

Fig. 8 Variation between average settlement due to rise in water table and with thickness of collapsible soil 
Fig. 9 Influence of thickness of collapsible soil on average settlement due to combined effects of water table rise and drip irrigation

\section{Table captions}

Table 1 Soil combinations used in experimentation

Table 2 Depth location of representative samples from boreholes and properties of collapsible soil 


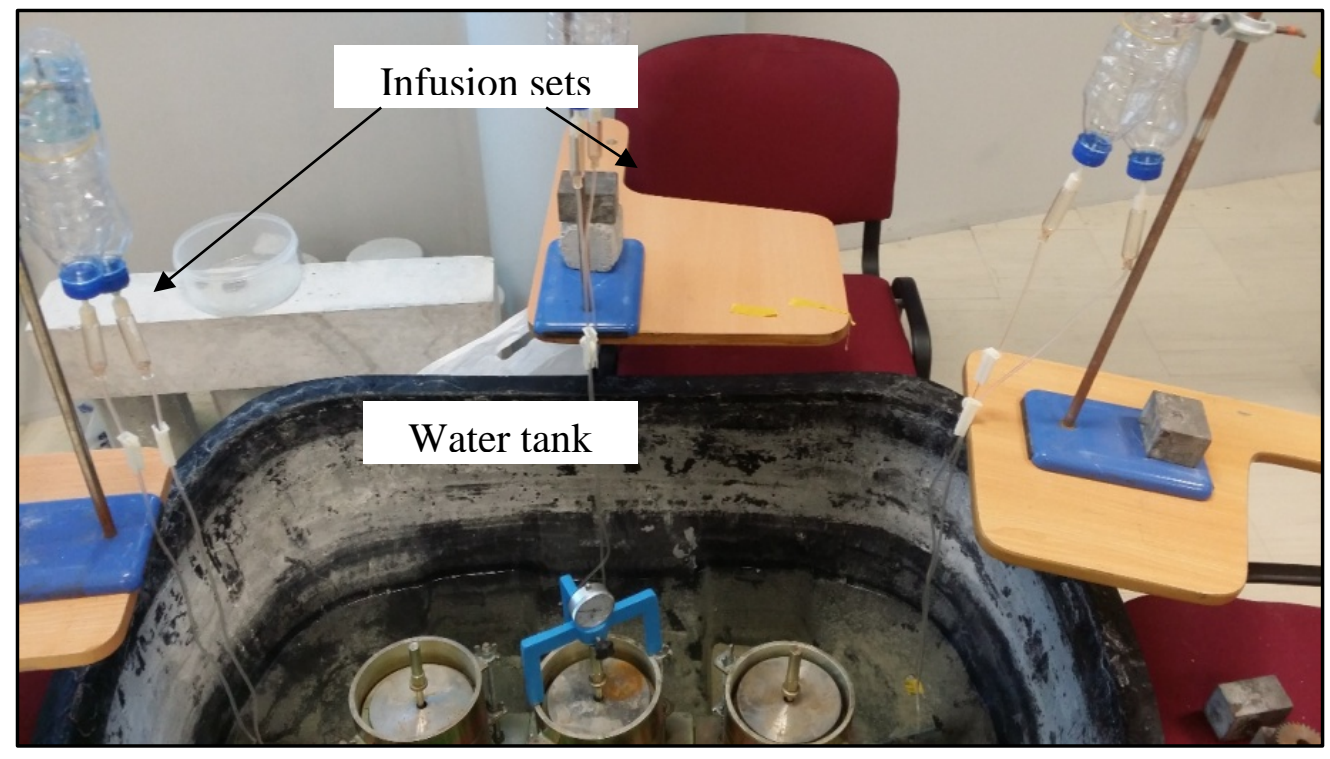

1 Purpose designed experimental arrangement for measuring settlement of collapsible soil under varying irrigation rates and water levels 


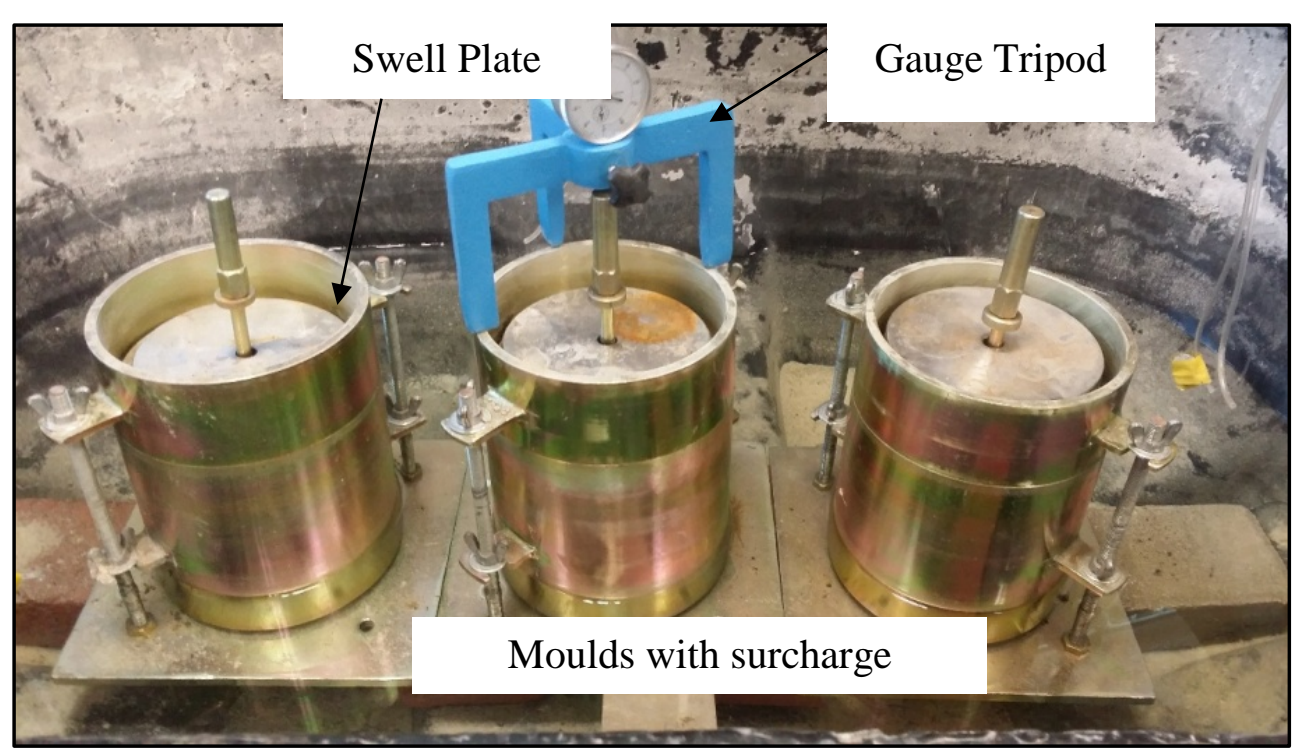

2 Monitoring of the initial gauge readings for soil in the dry state prior to start of irrigation 


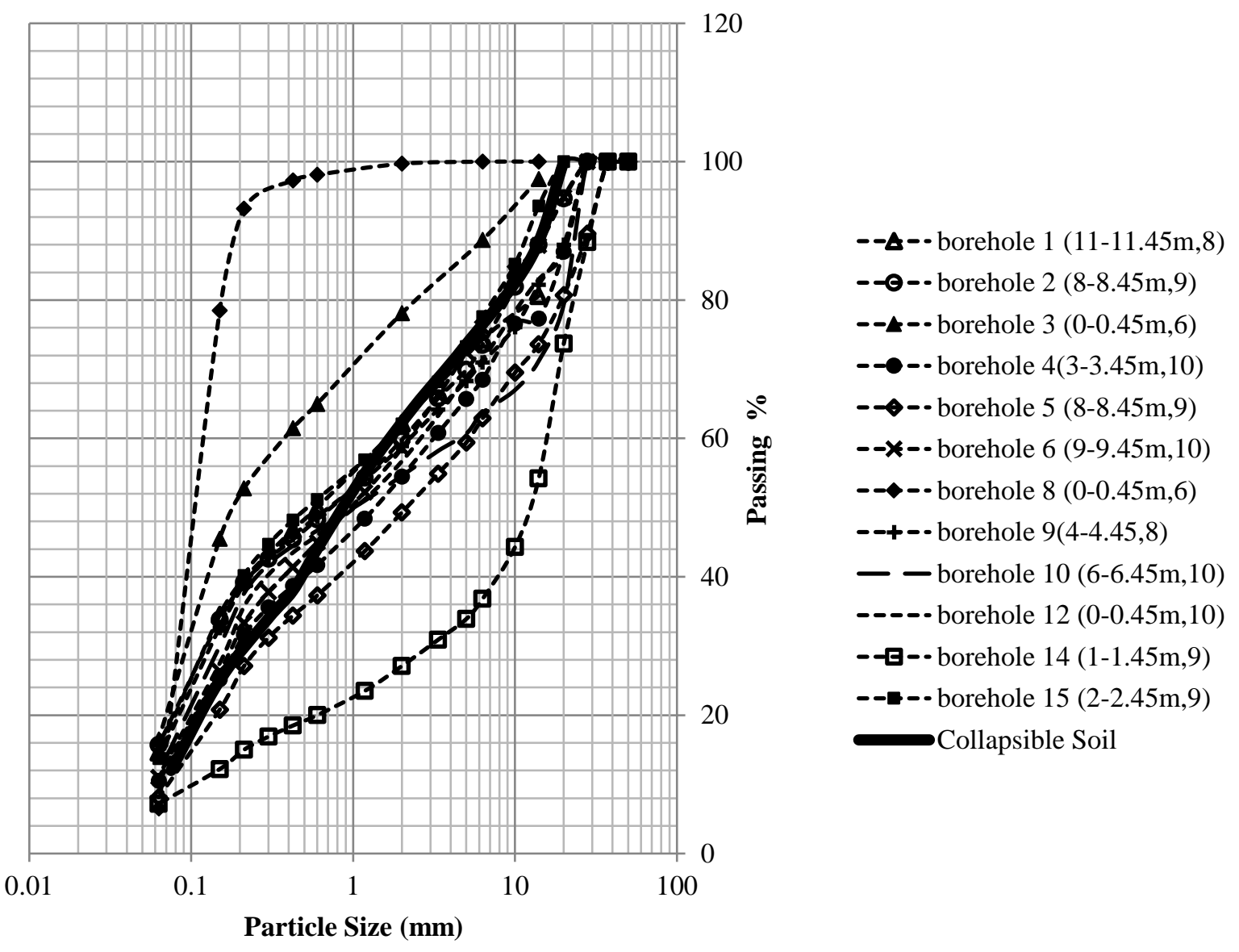

3 Grain size distributions of representative collapsible soil samples from 12 boreholes (sampling depths and SPT values shown in the legend) 


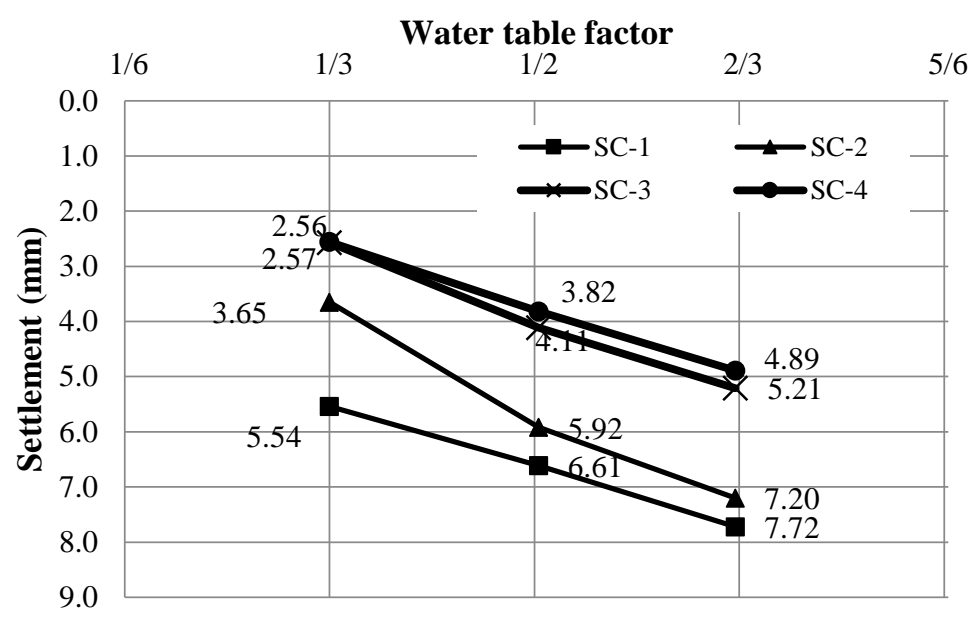

(a) $\gamma=17.5 \mathrm{kN} / \mathrm{m}^{3}$

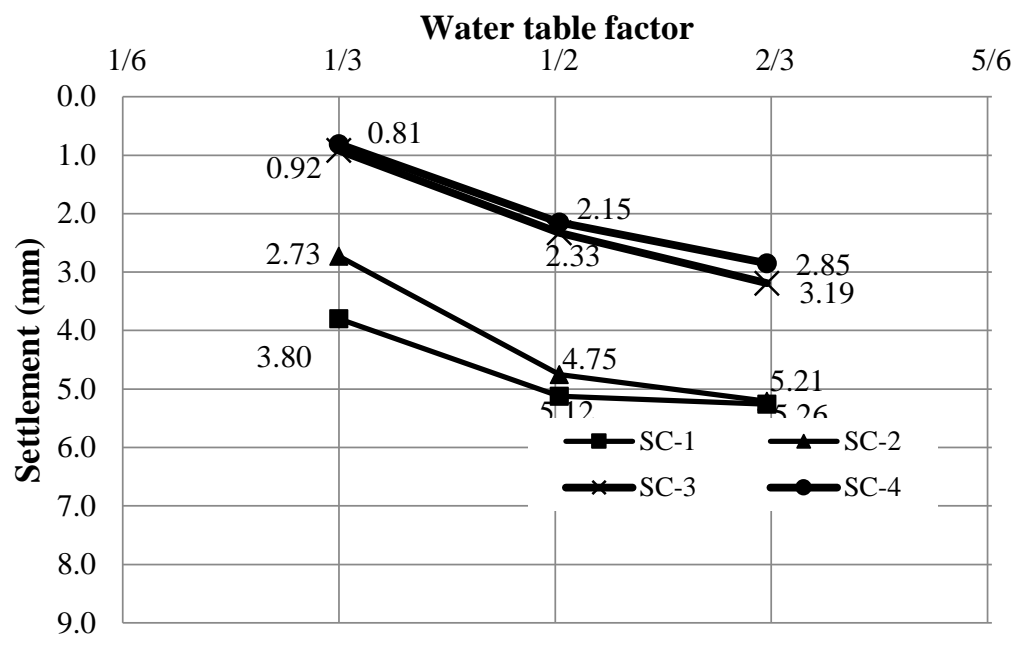

(b) $\gamma=18.0 \mathrm{kN} / \mathrm{m}^{3}$ 


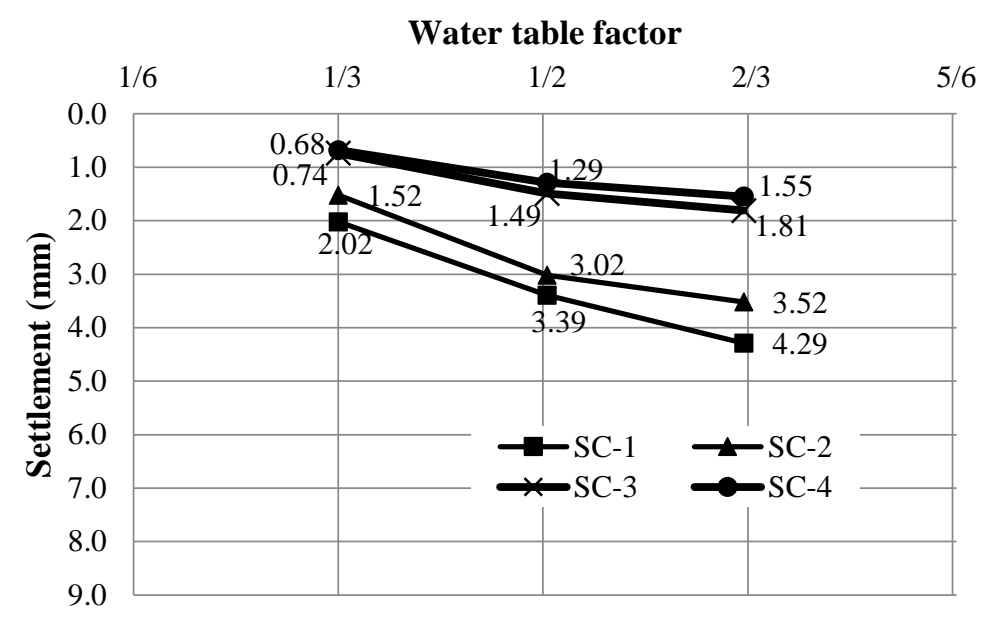

(c) $\gamma=18.5 \mathrm{kN} / \mathrm{m}^{3}$

4 Variation between soil settlement due to water table rise and water table factor (results for different soil densities: $17.5-18.5 \mathrm{kN} / \mathrm{m}^{3}$ ) 


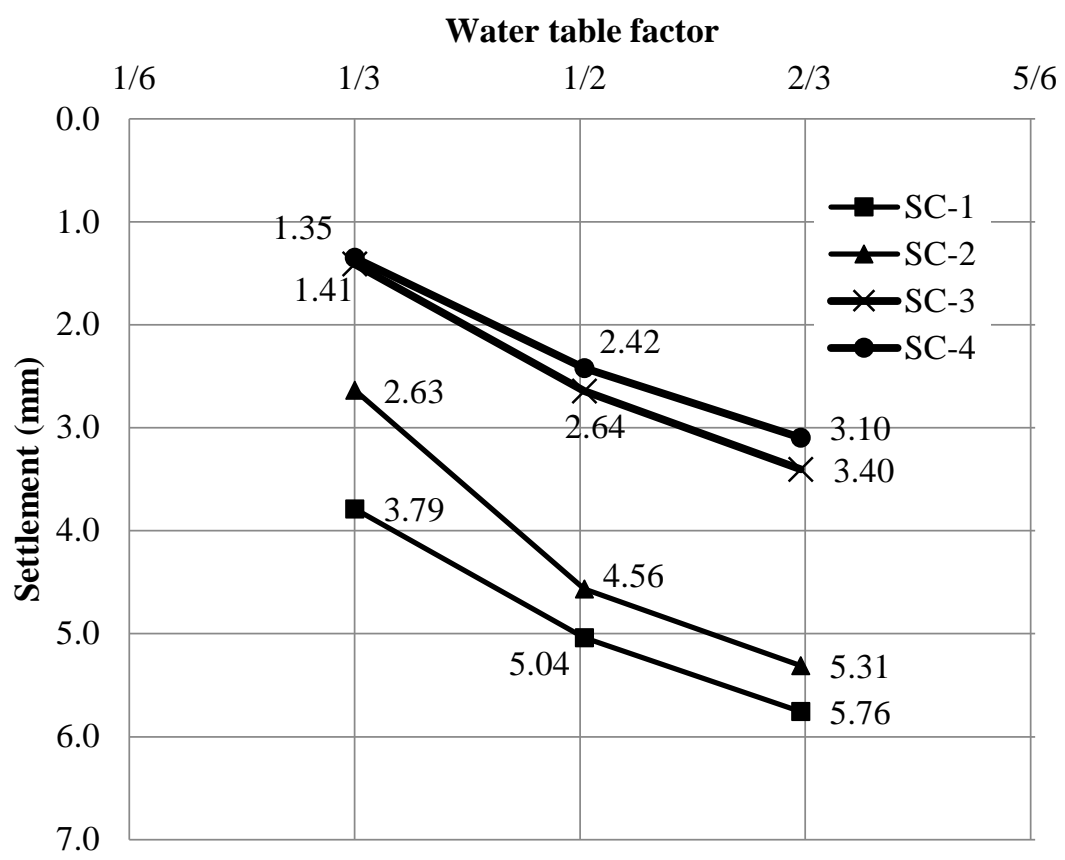

5 Variation between average soil settlement due to water table rise and water table factor 


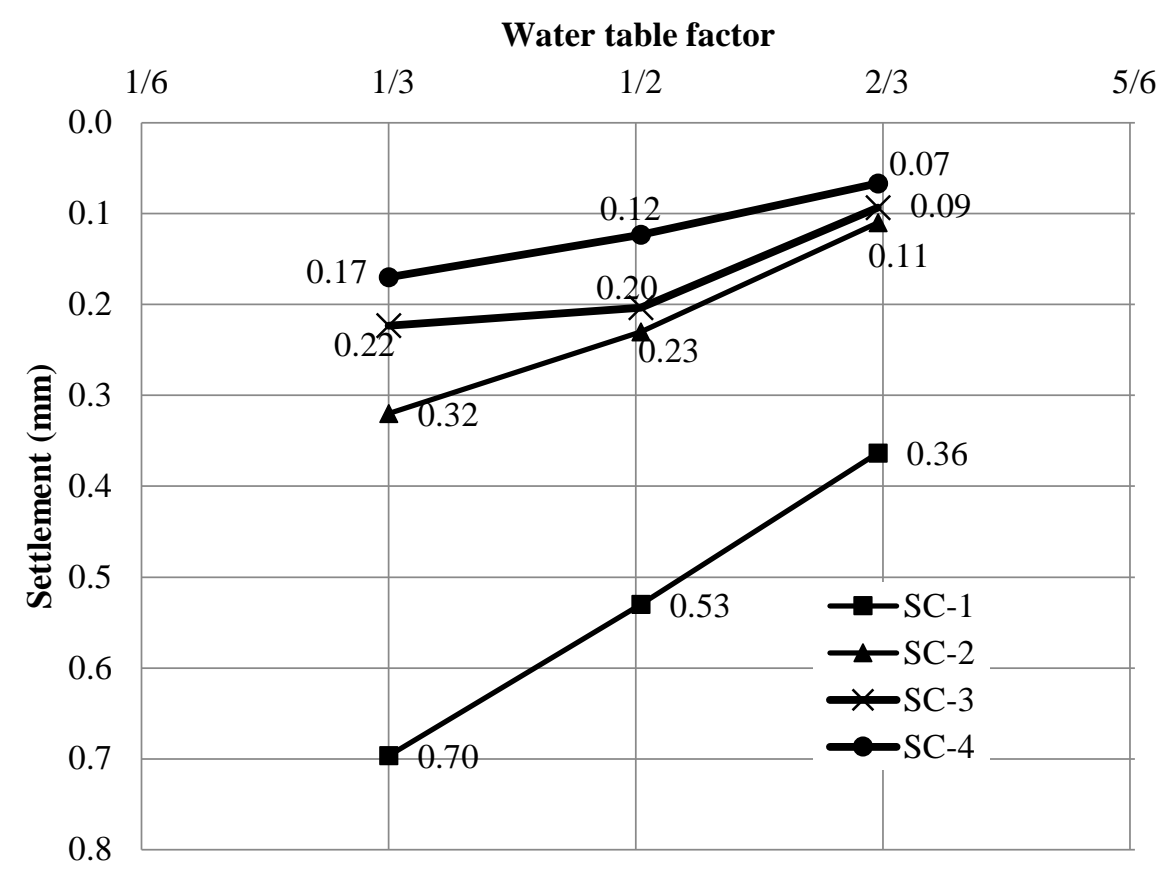

6 Variation between average soil settlement due to drip irrigation and water table factor 


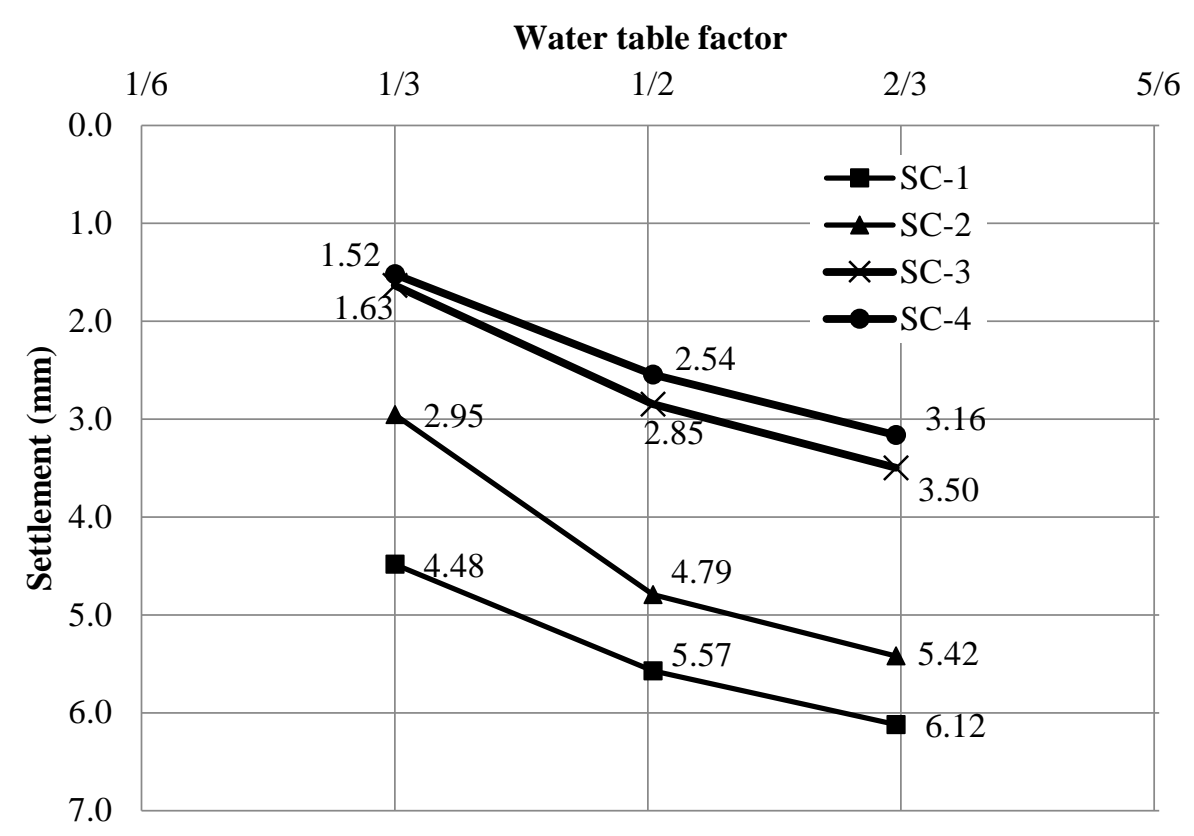

7 Variation of average soil settlement with water table factor due to the combined effects of water table rise and drip irrigation 


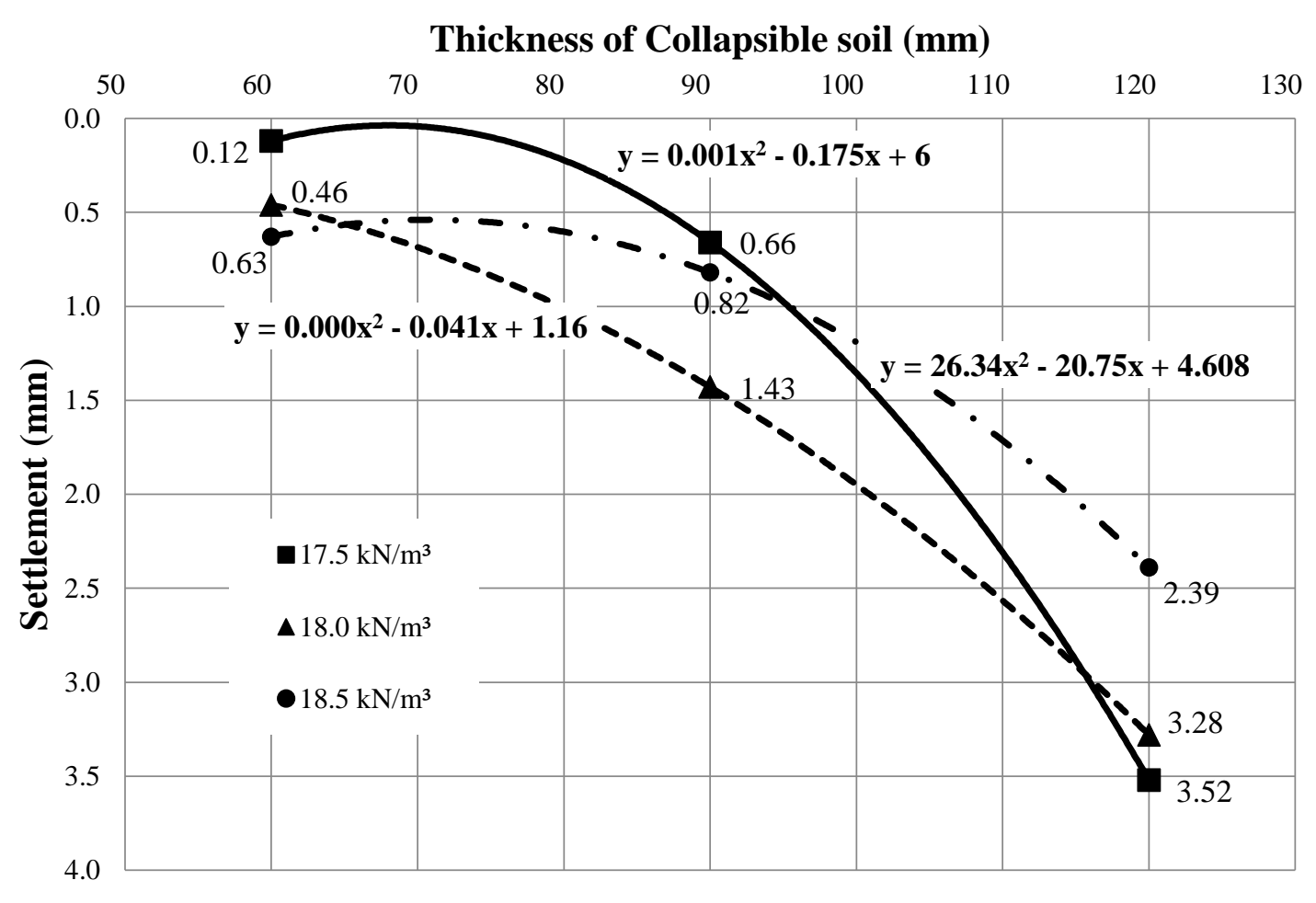

8 Variation between average settlement due to rise in water table and with thickness of collapsible soil 


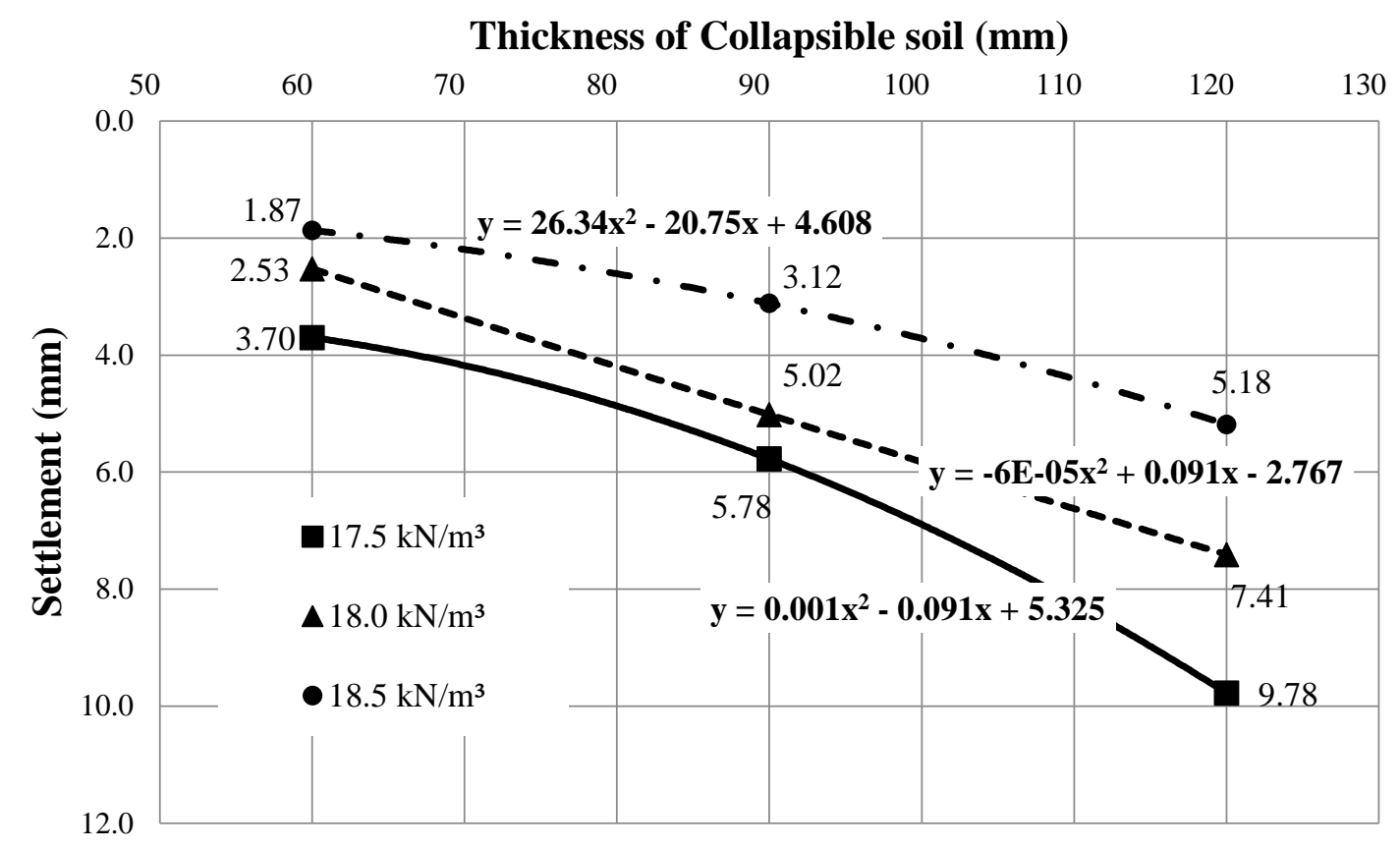

9 Influence of thickness of collapsible soil on average settlement due to combined effects of water table rise and drip irrigation 
Table 1 Soil combinations used in experimentation

Soil

Combination

Details

Soil

Combination

Details

(SC)

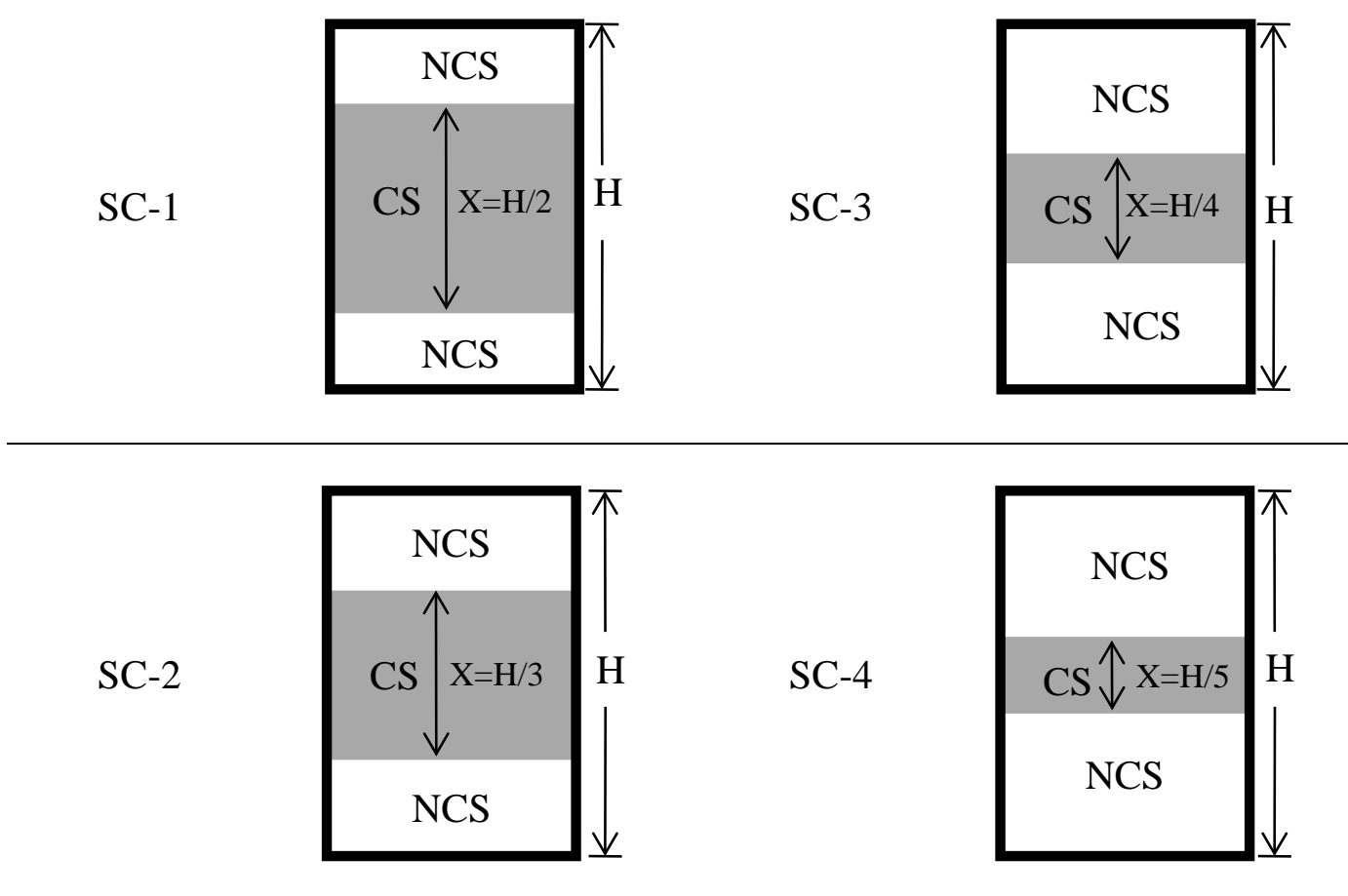

Note :

$\mathrm{H}$ - Height of the CBR mould (180mm)

NCS - Non-collapsible soil

CS - Collapsible soil 
Table 2 Depth location of representative samples from boreholes and properties of collapsible soil.

\begin{tabular}{|c|c|c|}
\hline Borehole Number & $\begin{array}{l}\text { Depth of } \\
\text { sampling } \\
\text { (m) }\end{array}$ & $\begin{array}{c}\text { SPT } \\
\text { N-Value }\end{array}$ \\
\hline 1 & $11.00-11.45$ & 8 \\
\hline 2 & $8.00-8.45$ & 9 \\
\hline 3 & $0.00-0.45$ & 6 \\
\hline 4 & $3.00-3.45$ & 10 \\
\hline 5 & $8.00-8.45$ & 9 \\
\hline 6 & $9.00-9.45$ & 10 \\
\hline 8 & $0.00-0.45$ & 6 \\
\hline 9 & $4.00-4.45$ & 8 \\
\hline 10 & $6.00-6.45$ & 10 \\
\hline 12 & $0.00-0.45$ & 10 \\
\hline 14 & $1.00-1.45$ & 9 \\
\hline 15 & $2.00-2.45$ & 9 \\
\hline Property of collapsible soil & \multicolumn{2}{|c|}{ Value } \\
\hline Specific gravity & \multicolumn{2}{|c|}{2.66} \\
\hline Plasticity characteristics & \multicolumn{2}{|c|}{ Non-plastic } \\
\hline Optimum moisture content & \multicolumn{2}{|c|}{$15.50 \%$} \\
\hline Maximum dry density & \multicolumn{2}{|c|}{$18.45 \mathrm{kN} / \mathrm{m}^{3}$} \\
\hline Permeability & \multicolumn{2}{|c|}{$8.86 \mathrm{E}-05 \mathrm{~m} / \mathrm{s}$} \\
\hline $\begin{array}{l}\text { Note : } \\
\text { SPT - Standard Penetration }\end{array}$ & & \\
\hline
\end{tabular}


